\title{
Using Learning Styles for Creating and Personalizing Educational Content in Ubiquitous Learning Environments
}

\author{
Rafael D. Araújo \\ Faculdade de Computação \\ Universidade Federal de \\ Uberlândia \\ rafael.araujo@ufu.br \\ Fabiano A. Dorça \\ Faculdade de Computação \\ Universidade Federal de Uberlândia \\ fabianodor@ufu.br
}

\author{
Taffarel Brant-Ribeiro \\ Instituto Federal de Educação, \\ Ciência e Tecnologia do Sul de \\ Minas Gerais \\ brant.ribeiro@ifsuldeminas.edu.br
}

\author{
Hiran N. M. Ferreira \\ Instituto Federal de Educação, \\ Ciência e Tecnologia do Sul de \\ Minas Gerais \\ hiran.ferreira@ifsuldeminas.edu.br
}

\begin{abstract}
The fact that people behave and learn in a different pace requires individual differences to be properly considered in the teaching/learning process. Among several cognitive theories that could be used for this purpose, a promising one is to explore the use of students' learning styles (LSs), with several research studies indicating that their use has positive impacts on learning outcomes. At the same time, Ubiquitous Learning Environments (ULEs) have the potential to make the multimedia authoring of Learning Objects (LOs) an automated process, resulting on even larger educational content repositories and increasing the need for more adequate presentation strategies to students. This article presents an approach for creating and personalizing LOs through a probabilistic proposal of the Felder and Silverman Learning Styles Model. A prototype of the proposed model was integrated into a ubiquitous educational platform and experimented in real settings. Results indicate the existence of correlations between different types of interactions carried out by students and their respective LSs.
\end{abstract}

Keywords: Educational Content Personalization; Learning Styles; Student Model; FSLSM; Ubiquitous Learning Environments.

Cite as: Araújo, R. D., Brant-Ribeiro, T., Ferreira, H. N. M., Dorça, F. A., \& Cattelan, R. G. (2020). Using Learning Styles for Creating and Personalizing Educational Content in Ubiquitous Learning Environments. Brazilian Journal of Computers in Education (Revista Brasileira de Informática na Educação - RBIE), 28, 133-149. 


\section{Introduction}

The use of technology in modern classrooms is currently a trend to assist and complement the teaching-learning process. In particular, the so called Ubiquitous Learning Environments (ULEs) have leveraged the automatic generation of educational content, primarily in the form of Learning Objects (LOs) that can be customized to best fit students' capabilities and limitations (Araújo, Brant-Ribeiro, Ferreira, Dorça, \& Cattelan, 2016; Greiff, Niepel, Scherer, \& Martin, 2016; Nguyen, Rienties, Toetenel, Ferguson, \& Whitelock, 2017).

One of the major challenges of computing applied to education lies in the ability to support environments adaptable to student needs. According to (Brusilovsky, 2001), intelligent resources for content retrieval and personalization can be used to improve the learning experience, resulting in adaptive educational systems. In order to be accomplished, such vision requires (i) a Student Model (SM) for mapping the cognitive capabilities of each student and (ii) a strategy associated to a cognitive theory that takes into account the individual differences among students for proper content adaptation. The former has been employed over the years (Self, 1990) and has proven effective in many situations (Li, Cohen, Koedinger, \& Matsuda, 2011; Thomson \& Mitrovic, 2009), which allows automated systems to direct new actions to guide the learning experience of each student. For the latter, one of the possible approaches regards the use of Learning Styles (LSs).

While some authors disagree with the efficacy of LSs (An \& Carr, 2017; Kirschner, 2017), several studies claim that their use has a potential positive impact on learning outcomes (Adkins \& Guerreiro, 2018; Alshammari, Anane, \& Hendley, 2015; El-Bishouty, Chang, Graf, Kinshuk, \& Chen, 2014; Faria, Almeida, Martins, Gonçalves, \& Figueiredo, 2015; Mahnane \& Hafidi, 2015). Our overall impression is that the criticism usually happens due to the fact that many LS models use binary classifications and, thus, students are classified in only one end of the available dimensions, without considering uncertainties inherent in the process. For instance, a given student could be classified as $60 \%$ verbal and $40 \%$ visual, instead of either only visual or only verbal (i.e., $100 \%$ visual or $100 \%$ verbal) as usually done. Moreover, the instruments used to assess LSs are mostly based on extensive questionnaires to be manually answered by students, a tedious process many times performed by students without the needed attention or even ignored at all.

In general, literature research shows that a considerable amount of effort has been put on some of the desirable requirements mentioned above. However, they have not been explored all together in a single and cohesive computational architecture. In this way, this article aims at exploring contextual, cognitive, social and collaborative aspects in online learning environments in order to offer adaptive learning features to students in ULEs. To handle uncertainties, our proposal employs a probabilistic approach of the Felder and Silverman Learning Styles Model (FSLSM) (Felder \& Silverman, 1988), with the addition of a semiautomatic technique for assessing LSs of students interacting in ULEs. Our model is initialized with values representing $50 \%$ of suitability for each LS. As students' LSs are assessed, inferences about their possible learning preferences are performed and the probabilistic model is updated. Furthermore, the 44 questions of the instrument used to manually assess the FSLSM, called Index of Learning Styles (ILS) (Felder \& Soloman, n.d.), are divided into different system's login sessions throughout the semester, so that the LS estimation process becomes less tedious for students. In each login session, four questions - one of each dimension of the model - are presented to students under analysis. Students also accumulate points in a gamification module for each answered question.

A prototype of the proposed model was integrated into a ubiquitous educational platform called Classroom eXperience (CX) (Araújo et al., 2017; Ferreira, Brant-Ribeiro, Araújo, Dorça, \& Cattelan, 2016), which has been used a case study in real settings. The platform includes the 
aforementioned social and collaborative functionalities, as well as content personalization and gamification features. Over this case study, we performed experiments during a school semester with 43 students of Computer Science and Information Systems majors. Preliminary results indicate the existence of correlations between different types of interactions carried out by students and their respective LSs.

The remainder of this article is organized as follows: Section 2 brings the theoretical background associated to the proposal; Section 3 discusses related work; Section 4 presents the architecture of the proposed approach, detailing the associated SM and explaining how the content adaptation process works; Section 5 details the integration of our model to a real ULE and its experimental setup; Section 6 discusses the results; and, finally, Section 7 presents conclusions and future work.

\section{Background}

Mark Weiser (Weiser, 1991) coined the concept of Ubiquitous Computing in the late 1980s to describe the increasingly ubiquitous integration of computing devices into people's daily lives. One of its research subareas, called Capture \& Access (C\&A), creates applications that record daily activities for future review. In educational contexts, the use of technology can help teachers and students in teaching/learning processes through automation of pedagogical tasks that can be accessed in different contextual moments, which gives rise to so-called Ubiquitous Learning Environments (ULEs).

Physical classrooms equipped with computing devices, such as electronic whiteboards, multimedia projectors, microphones, and video cameras, produce multimedia artifacts capable of simulating experiences lived in the classroom in a non-intrusive way. (Abowd et al., 1996) proposed a four-phases design for C\&A applications: (i) pre-production, when instructors prepare the base content for the lecture; (ii) live recording, when multiple media streams are captured through those electronic devices; (iii) post-production, when all captured streams are synchronized and stored; and, (iv) access, stage in which students access the content for future study. In addition, a fifth phase, called extension, can also be included to allow instructors and students to enrich the material with supplementary information (Pimentel, Ishiguro, Kerimbaev, Abowd, \& Guzdial, 2001). This kind of environment is a potential producer of Learning Objects (LOs) and is capable of automatically or semiautomatically creating metadata with the power to become a source of information for content personalization and recommendation processes with respect to each student needs and preferences.

LOs have become fundamental pieces to remodel traditional pedagogical practices (Wiley, 2000) (Wiley, 2000). According to IEEE, LOs are digital or non-digital entities that can be used in learning contexts (IEEE, 2002). The term reuse is often added to this definition, which makes the use of standards a necessity. In this way, organizations like IEEE, IMS Global Learning Consortium, and ADL (Advanced Distributed Learning), have produced specifications and standards to address this need. The IEEE Learning Object Metadata (IEEE-LOM) (IEEE, 2002) is a widely used standard to represent metadata of LOs in the sense of resource description, discovery, and reusability (Van Assche, Campbell, Rifón, \& Willem, 2003). The IEEE-LOM support content interoperability among repositories and enables automated content search and retrieval.

The IEEE-LOM is structured into nine categories: General, Life Cycle, Meta-Metadata, Technical, Educational, Rights, Relation, Annotation, and Classification. Each data element has a name, a description, a datatype and maximum size, and the order inside its parent node. For this work, the Educational category is one of the most important as it brings educational and pedagogical characteristics, such as "Learning Resource Type”, “Interactivity Type”, 
"Interactivity Level”, "Semantic Density”, among others. In addition to the vocabulary provided by the IEEE-LOM, this work also includes the Customized Learning Experience Online (CLEO) extensions (CLEO, 2003) in order to add higher semantic meanings to the "Learning Resource Type" field, namely: additional resource, analogy, assessment, assessment item, attractor, community, definition, demonstration, example, feedback, glossary, guidance, guideline, illustration, importance, introduction, non example, note, objective, outline, overview, practice, prerequisite, presentation, recall, reference, reinforcement, scenario, and summary. It is important to note that including a new vocabulary only adds new possible values to the default ones and does not change the structure of the metadata, which maintains its reuse property.

Many studies from the literature indicate that students learn differently from one another (Brusilovsky, 2001; Essalmi, Ayed, Jemni, Graf, \& Kinshuk, 2015; Graf, Chang, Kersebaum, Rath, \& Kurcz, 2014). Teaching strategies that take into account students' individual differences have been studied for some time, such as Learning Styles (LSs) models. An LS model classifies learners according to the way they perceive and process information received in educational contexts. There are many LS models that describe different aspects on how students prefer to learn. Such models can determine how individuals interact and react in a learning environment, reflecting their real preferences (Felder \& Silverman, 1988). Some studies claim that students' performance is improved if the learning environment provides adaptivity based on LSs (Alshammari et al., 2015; El-Bishouty et al., 2014; Yang, Hwang, \& Yang, 2013).

It is also possible to find studies that disagree on the effectiveness of LSs, as in (An \& Carr, 2017; Kirschner, 2017). In general, criticisms are related to the classification of learners into only one LS without considering any mixed preferences or, even without considering that such preferences can actually change from one style to another over time, especially when only certain types of content are presented to students regarding those antagonistic models.

Nonetheless, the approach used in this work adopts a probabilistic alternative proposed by (Dorça, Lima, Fernandes, \& Lopes, 2013) to indicate that an LS is not a unique, neither a fixed choice, which is based on the widely used Felder and Silverman Learning Style Model (FSLSM) (Felder \& Silverman, 1988). The FSLSM classifies each student into eight different LSs, which are grouped into four dimensions: Active/Reflective, Sensing/Intuitive, Visual/Verbal, and Sequential/Global. This model is based on the idea that each student has a preference (or tendency) for one of the two LSs of each of the four dimensions, which represents a noteworthy characteristic of this model that allows Adaptive Educational Systems to create more detailed Student Models (SM) to provide a more accurate content personalization and adaptive experiences.

The FSLSM dimensions incorporate individual characteristics related to perception, processing, presentation, and organization of the information during the learning process. The perception dimension (Sensing/Intuitive LS) classifies students according to the way they perceive the content (concrete vs abstract content). The processing dimension (Active/Reflective LS) classifies students into proactive individuals or those who have a more passive posture. The input dimension (Visual/Verbal LS) indicates how students prefer to receive the content (visual vs verbal). Finally, the organization dimension (Sequential/Global LS) indicates how students prefer the content to be organized.

Briefly, each dimension can be described as:

- Processing (Active/Reflective LS): classifies students into individuals who prefer more practical activities and group work in their learning process (active ones), or individuals who practice a more passive posture (reflective ones);

- Perception (Sensing/Intuitive LS): classifies students according to how they perceive the content. Sensing students prefer a more concrete content, such as facts and examples, 
while intuitive ones prefer a more abstract content, such as theories and mathematical models;

- Input (Visual/Verbal LS): indicates how students prefer to receive the content. Visual students prefer visual resources while verbal students prefer textual or spoken content;

- Organization (Sequential/Global LS): indicates how students prefer the content organization. Sequential students prefer a progressive and sequential presentation while global students prefer to get an overview of what is taught, with freedom to navigation through the content.

In most cases, manual instruments are used for assessing students' LSs. The Index of Learning Style (ILS) is a 44-questions questionnaire used to identify students' LSs according to the FSLSM. Each of the four dimensions contains 11 questions with two alternatives each. The output consists of four values ranging from -11 to +11 that strength a preference for one side of the dimension. Although it is a statistically validated instrument (Felder \& Spurlin, 2005), its manual filling causes displeasure and lack of motivation, which can lead to possible imprecise answers. On the other hand, there are fully automatic approaches for detecting LS, but the results of assessed LSs are often different in both methods (Ahmad, Tasir, Kasim, \& Sahat, 2013). Therefore, the use of a self-report instrument may be used to adjust the model for better results.

\section{Related Work}

Over the years, several computational architectures have been proposed with the purpose of personalizing educational content. One worth mentioning is the architecture proposed by (Vidal, Costa, Silva, Araújo, \& Ferreira, 2016), an adaptive hypermedia-based approach for assisting students to accomplish their activities in Accounting courses. Their approach takes into account a domain model, representing accounting knowledge, a student model that considers static and dynamic information, and an adaptive model which provides an adaptive navigation mechanism based on student model. However, the latter does not consider LSs for adaptation neither proposes an approach for supporting LOs authoring.

The Generalized Intelligent Framework for Tutoring (GIFT) (Sottilare, Brawner, Sinatra, \& Johnston, 2017) is an adaptive tutoring architecture that includes a myriad of features, such as authoring tools, learner model, sensor processing module, pedagogical module, among others. Some differences from this work may be pointed out. As we noticed, GIFT does not consider either refinement or collaborative content enrichment. Also, it does not consider the CLEO extensions and does not provide a way to classify LOs according to LSs.

In the context of ULEs, GlobalEdu (Barbosa et al., 2013) is an architecture based on ubiquitous computing resources that explores the concept of LO, also represented in the IEEELOM standard, to explore pedagogical opportunities in a context-aware environment. Their approach matches learners with similar or complementary interest to stimulate their interaction. Although GlobalEdu also adapts LOs according to students' LS, the CLEO extensions are not considered and, as far as we know, there is no collaborative feature for content enrichment.

Youubi (Monteiro, Oliveira, Gomes, \& Mendes Neto, 2017) is an platform designed as a component-oriented architecture and accessible through mobile, web, smartwatch and iDTV platforms. It is a platform that provides support for formal and informal learning by means of contextual, social, and gamification features. Their architecture focuses on recommendations for elementary entities, such as Person, Location, Event, Challenge, and Group. The approach proposed here focuses on personalized and individual content adaptation as well as LOs authoring structured according to the IEEE-LOM standard. 
An adaptive content delivery framework for u-Learning environments was proposed by (Zhao \& Okamoto, 2011). This framework gets original PowerPoint files and delivers adaptive content based on learners' context, preferences and social networks information. They developed the so called AubiLearn mobile system to evaluate their approach.

An adaptive framework to suggest learning paths that meet students learning objectives was proposed by (Onah \& Sinclair, 2015). When students register in the system, they answer a survey to capture their learning objectives. Based on that, learning paths were created to match students' objectives and LOs concepts. When answering multiple-choice questions, students receive an instant feedback and a recommended content based on their performance.

(Mahnane, Laskri, \& Trigano, 2013) proposed an adaptive educational hypermedia system based on learner's thinking and learning styles. It was structured in three basic components: the domain model, the learner model and the adaptation model. The domain model stores, organizes and describes the learning content in 12 types. The learner model gathers information about students' goals and preferences, thinking and learning style, and knowledge and performance. Lastly, the adaptation model contains a set of rules that specifies how the learners' knowledge and thinking style modify the presentation of the content.

(Boticario et al., 2012) have proposed a framework for content recommendation based on international standards and interoperable components which are integrated through a serviceoriented architecture. This framework is part of the EU4ALL project, founded by a European Consortium composed of 15 institutions from 8 different European countries. They have developed the dotLRN LMS (Santos, Boticario, Raffene, \& Pastor, 2007) which provides a set of social and collaborative features such as blogs, discussion forums, chats, and study groups. Their SM stores personal information, preferences, learning styles according to the FSLSM, goals and competencies, progress and some indicators about attention, memory and time management. Their work is quite related to the proposed here, however, some differences can be pointed out. First, the framework does not consider hierarchical LOs with different granularity levels. Also, they are not produced in a ubiquitous environment.

The LAES (Libyan Adaptive Education System) (Alzain, Clark, Ireson, \& Jwaid, 2018) is a web-based adaptive system that considers LSs in their student model to adapt the educational content. A manual instrument is used to assess students' LSs when they first log in the system. Among the differences of this work, it is possible to note that they use a different LS model which is not probabilistic and the LOs authoring is a manual process. However, based on their results, they also claim that LSs dimensions must not be handled as dichotomies.

\section{Proposed Approach}

As previously mentioned, Ubiquitous Learning Environments (ULEs) have the potential to create a huge amount of Learning Objects (LOs) that could become useless if they are not structured to fit students' needs. In this way, simply creating content in those environments is not enough. It is necessary to create mechanisms that allow them to be properly structured and stored so that they can be included in content personalization processes.

As ULEs blend real and virtual learning environments, both instructor and student play key roles in the proposed approach. Instructors are responsible for creating content in the LO authoring process that is collaboratively refined with the help of students. It makes the LO authoring process less arduous and time-consuming for instructors. Since such content represents lectures taught in classrooms, computational devices also assist in gathering information to fill out its metadata. It happens in the pre-production and live recording phases of the C\&A design. Once properly structured and stored during the post-production phase, students interact with LOs in the access 
phase and eventually contribute to content enrichment in an extension phase. In our approach, the post-production phase is dynamic and takes place on-the-fly together with the access phase that provides feedback to iteratively construct and evolve the student model in order to provide a more adequate personalization. Figure 1 shows an overview of this process, in which dotted areas represent user interfaces, dotted arrows indicate the direction of users input data, blue arrows illustrate the flow between system components, and asterisks shows the correspondence with the C\&A phases.

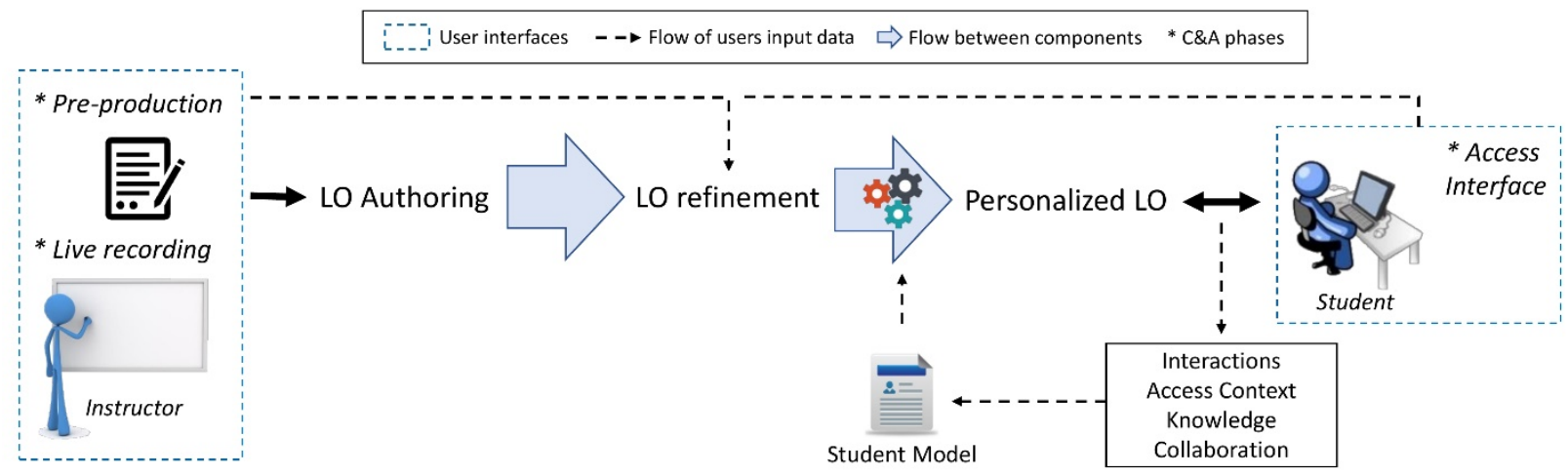

Figure 1 - Overview of the LO authoring and personalization process.

The proposed approach will be detailed in the next subsections, separating the student model that includes important information for personalizing the educational content, and the content adaptation process.

\subsection{Student Model}

To be able to provide personalized LOs to students, it is important to define which individual characteristics will be gathered and how they should be stored. In this way, a Student Model (SM) is created to represent students' behavior and skills in order to identify what is really relevant for each student.

An SM is one of the fundamental components for personalizing educational content and it should represent not only students' knowledge but rather reflect, as closely as possible, their reasoning process (Clemente, Ramírez, \& de Antonio, 2011). For instance, a student may learn better by practical content while another student may do better with abstract content. Additionally, students' progress and contextual characteristics of the learning environment are also important for the learning process.

In this way, the SM proposed here takes into account students' personal information (personal data and preferences that includes their learning style), online behavior (interactions while using the system), access context (such as type of device, bandwidth and screen resolution, date and location, reason of access and available time), and progress (knowledge information that includes attempts to answer quizzes). These characteristics are stored in an ontology that represents the SM (Ferreira et al., 2016).

In this work, we are interested in the representation of the Learning Styles (LSs), since it is focused on the LO personalization based on this characteristic. Thus, as an LS is an information related to the learning of individuals and it can be used as an individual preference parameter for content personalization, this work uses a probabilistic proposal to store students' LSs based on the FSLSM (Dorça et al., 2013), which is shown by Equation 1.

$$
\begin{gathered}
L S_{\text {student }}=\{(\operatorname{PrA}, \operatorname{PrR}),(\operatorname{PrS}, \operatorname{PrI}),(\operatorname{PrVi}, \operatorname{PrVe}),(\operatorname{PrSeq}, \operatorname{Pr} G) \\
\operatorname{PrA}+\operatorname{PrR}=1, \operatorname{PrS}+\operatorname{PrI}=1, \operatorname{PrVi}+\operatorname{PrVe}=1, \operatorname{PrSeq}+\operatorname{Pr} G=1\}
\end{gathered}
$$


where,

$\operatorname{PrA}$ : likelihood of preference for the Active LS;

$\operatorname{PrR}$ : likelihood of preference for the Reflective LS;

PrS: likelihood of preference for the Sensing LS;

PrI: likelihood of preference for the Intuitive LS;

PrVi: likelihood of preference for the Visual LS;

PrVe: likelihood of preference for the Verbal LS;

PrSeq: likelihood of preference for the Sequential LS;

$\operatorname{PrG}$ : likelihood of preference for the Global LS.

Eight decimal values are stored in pairs - one pair for each dimension of the model. Each LS is a complementary value to its respective pair in the same dimension, for example: since Active LS and Reflective LS belong to the Processing dimension, the sum of the values PrA and $\operatorname{PrR}$ cannot exceed 1, i.e., the values of each dimension does not exceed $100 \%$. This representation gives a probabilistic nature to LS, which means that the LS of each student is not a single choice and it is not even fixed. It means, therefore, that students tend to prefer one or more LSs with a certain probability and this preference may evolve over time. Table 1 shows an example of the stored LS information for a fictitious student with the probability distribution for each dimension of the model.

Table 1 - Example of the LS information of a fictitious student.

\begin{tabular}{|c|c|c|c|c|c|c|c|}
\hline \multicolumn{2}{|c|}{ Processing } & \multicolumn{2}{|c|}{ Perception } & \multicolumn{2}{|c|}{ Input } & \multicolumn{2}{|c|}{ Organization } \\
\hline $\operatorname{PrA}$ & $\operatorname{PrR}$ & $\operatorname{PrS}$ & $\operatorname{PrI}$ & $\operatorname{PrVi}$ & PrVe & PrSeq & $\operatorname{PrG}$ \\
\hline 0.64 & 0.36 & 0.82 & 0.18 & 0.41 & 0.59 & 0.50 & 0.50 \\
\hline
\end{tabular}

Moreover, each LS is initialized with a 50\% value to minimize the cold start problem, which indicates that the system does not know the students' preferences. In order to prevent students from getting tired and responding the instrument with inaccurate information, the ILS is used in a distributed way among usage sessions of the system during the semester. By enabling this feature, students enrolled in the course receive an informative text about the ILS, which is displayed only on their first login session (Figure 2(a)). Then, four questions - one from each dimension - are presented to students through a notification icon flagged with a red color in each new login session (Figure 2(b)). 


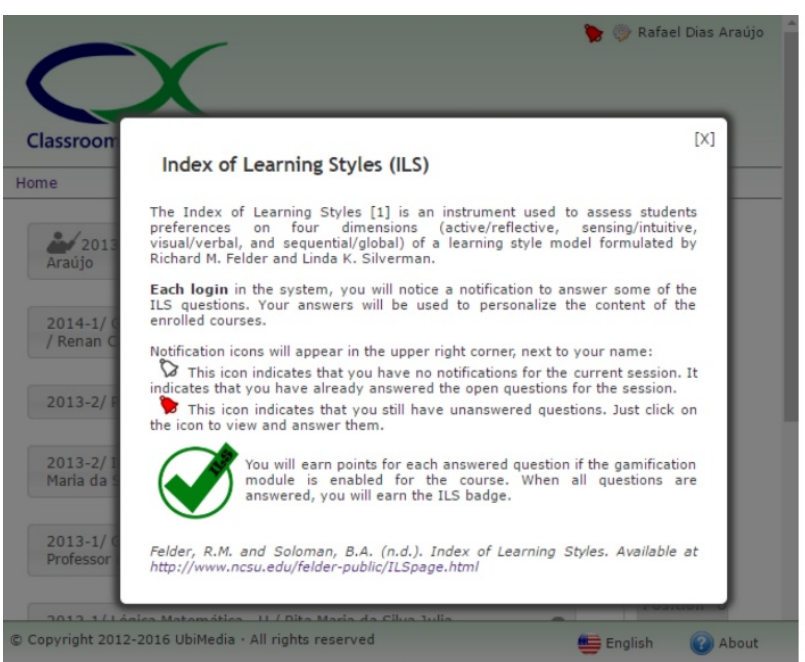

(a)

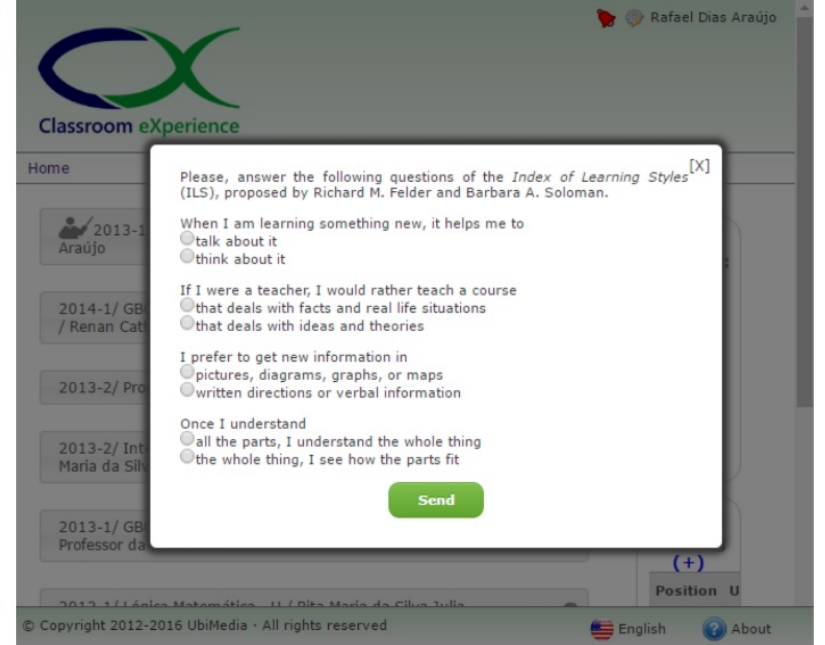

(b)

Figure 2 - (a) Dialog box about the ILS; (b) Four ILS questions.

The preference probability of the LS corresponding to the answered alternative is increased by $I=P / Q$, where $P$ is the initial probability of each $L S$, that is $50 \%$, and $Q$ is the number of questions related to each dimension. In this way, every time students answer a question, 50/11 points ( $4.55 \%)$ are added to the LS represented by the answer and its opposite LS is updated to the complementary value to reach $100 \%$ in that dimension. Still aiming to encourage students to answer the questionnaire, each answered question gives some points to the gamification module. Once answered all 44 questions, students earn a specific badge for this task, the same as the one presented in Figure 2(a).

\subsection{Content Adaptation}

Consistent LOs (content itself and metadata) provide meaningful information that may be used to create personalized experiences with educational content according to students' preferences and their individual differences. Yet, it is still an arduous and time-consuming task. Lectures recorded in ULEs can be regarded as LOs since they are pieces of educational content. However, these LOs are coarse-grained as they represent a whole lecture, which is typically more than 1-hour long.

Therefore, one more step was included in the LO creation process to refine them through collaborative features. When the content is available to students, both students and instructors are allowed to label subjects within a lecture using a bookmarking feature, which is used to split the lecture into smaller LOs. Each lecture consists of a set of slides that can be grouped into different subjects, or topics. Knowing that, a single lecture generates many other LOs, which have been structured in three hierarchical levels: lecture, subject, and slide. A lecture consists of several subjects, which are composed of several slides (Araújo et al., 2016; Araújo, Brant-Ribeiro, Freitas, Dorça, \& Cattelan, 2014).

Theoretically, a lecture can be defined as a set of $n$ slides, with $i$ slides representing some introductory content (at the beginning of the lecture) and $n$ - $j$ slides representing some concluding content (at the end of the lecture). Additionally, this same lecture could be divided into $k$ subjects. In this way, LOs with different granularity are created: one LO for the whole lecture, each subject represents other LOs, and, finally, one LO for each subject, and one LO for each slide, counting $k+n+1$ LOs in total.

In this work, we use the IEEE Learning Object Metadata (IEEE-LOM) standard (IEEE, 2002) as a base schema to represent the LO metadata. Additionally, other values with higher semantic meanings proposed by CLEO extensions (CLEO, 2003) were included for the "Learning Resource Type" field. Nonetheless, the reuse property is maintained. Further, the proposed 
architecture also plays a role as a producer of LOs, not only a consumer, it means that it does not depend on finding LOs in external repositories.

The LS estimation of LOs is computed by a set of heuristic rules that map the vocabulary of a subset of the IEEE-LOM fields to the FSLSM (Araújo, 2017; Dorça, Araújo, Carvalho, Resende, \& Cattelan, 2016), which indicate the probability (or tendency) of the respective LO being matched with each LS of the FSLSM. These rules are checked and the proportionality of rules that matches the learning resource type of each LS dimension is stored by eight numeric values - two for each LS dimension - for each LO. Thus, the LO relevance to each student is computed as the sum of values obtained by the LO in each of the eight LS dimensions multiplied by the likelihood of preference of each LS stored in the student model (Equation 1).

As an example, imagine a lecture to teach repetition structures in the context of computer programming. First, the instructor could have prepared a set of introductory content (such as lecture's title and goal, and agenda). Then, the content could be divided, for example, into different subject matters, such as "For Loops", "While Loops", "Do While Loops", among others. Each subject may be presented through different learning resources, such as textual or visual definition, example, simulation, etc. Finally, the lecture could have a set of concluding content that includes the lecture's summary and references, as shown by Figure 3(a). At a certain point in the content access phase, be a specific student with who has tendencies for Sensing and Visual LS, the relevance computation of LOs will be higher for the objects that best fit this student profile. In this sense, each lecture subject will be internally rearranged to show LOs that fit his/her preference in the first place, as shown by Figure 3(b).

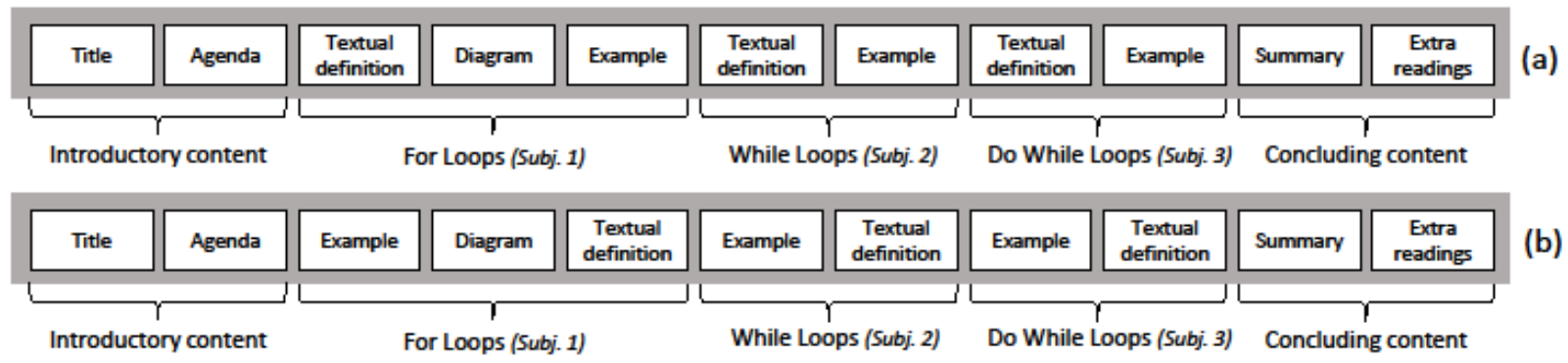

Figure 3 - Example of a personalized lecture for teaching repetition structures.

\section{Research Design}

The proposed approach was implemented into a ubiquitous educational platform called Classroom eXperience (CX) (Araújo et al., 2017; Ferreira et al., 2016), which has been used as a case study in real settings ${ }^{1}$. The platform includes social and collaborative functionalities as well as content personalization and gamification features.

Through its use, instructors prepare their lectures, which are recorded in the classroom with the aid of computational devices such as electronic whiteboards, multimedia projectors, microphones, and video cameras. Captured lectures are made available to students via Web through an adaptive hypermedia application. Resulting LOs are automatically related to their metadata information in the IEEE-LOM standard. Figure 4 shows an example of a captured lecture made available to students. As can be observed, it is possible to indicate which learning resource types each slide contains as well as indicate its importance through stars. In addition, instructors can create multiple-choice questions (quizzes) related to specific points of the lecture.

\footnotetext{
${ }^{1}$ Approved by the Ethics Committee of Federal University of Uberlândia.
} 


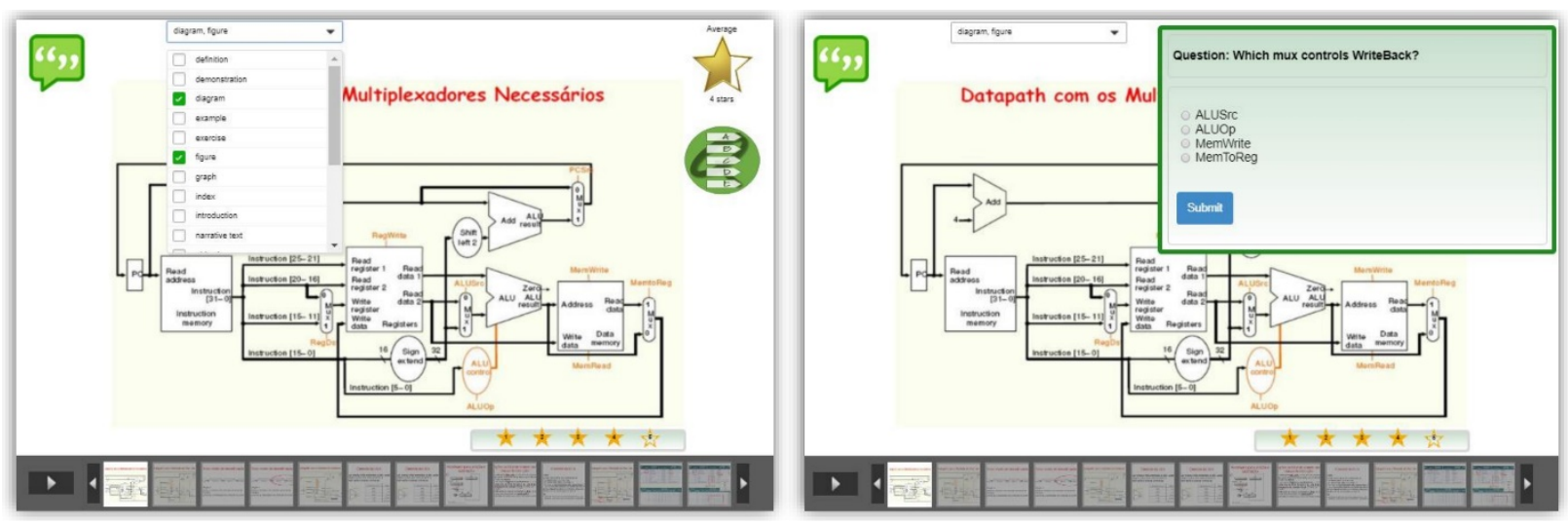

Figure 4 - Example of a captured lecture during the access phase.

The experiment was performed during a school semester by students of Computer Science and Information Systems majors from a Brazilian federal university, specifically from two different courses: Human-Computer Interaction (HCI) and Computer Architecture and Organization (COA). Table 2 shows the number of LOs created in each course after the end of the semester.

Table 2 - Number of LOs created in the CX platform for each course.

\begin{tabular}{cccc}
\hline Course & Lectures $^{\mathbf{1}}$ & Subjects $^{\mathbf{2}}$ & Slides/Lecture $^{\mathbf{3}}$ \\
\hline COA & 21 & 35 & $\sim 44$ \\
HCI & 14 & 16 & $\sim 60$ \\
\hline
\end{tabular}

${ }^{1}$ Lectures: number of LOs representing all lectures of the course.

${ }^{2}$ Subjects: total number of subjects created in the course.

${ }^{3}$ Slides/Lecture: average number of slides in each lecture.

In total, 57 students participated in this study: 23 students were enrolled in the HCI course and 34 students were enrolled in the COA course. First, a pretest - 10 multiple-choice questions prepared by each instructor - was initially applied to analyze students' previous knowledge in each domain. At the end, only students who took the pretest were evaluated, resulting 43 students (19 in the HCI course and 24 in the COA course). Their results in the pretest served as a baseline and were later compared with the scores obtained in a posttest, with the difference between them revealing the learning gain (Bonate, 2000).

For both the prior knowledge data and the LS information, the Shapiro-Wilk test was applied to check if samples were normally distributed. Due to most of the samples presenting nonnormal residuals, it was decided to check correlations between the scores obtained by students and their LSs using the Spearman's rank correlation coefficient (Spearman's $\rho$ ). Then, within each sub-sample, the Spearman's rank correlation was used again in order to identify possible correlations with different interaction types carried out by students. In this study, two interaction types were analyzed: (i) quiz answering, which indicates the number of attempts to answer multiple choice questions created by instructors, and (ii) collaborative activities, which indicates the number of interactions performed in slides rating activities as well as classification of learning resource types in each slide. According to the FSLSM, primarily active activities are directly related to the Active and Sensing styles (from two different dimensions of the model). In addition, features such as slides rating and classification involve graphic elements that could arouse the interest of students with a tendency to the Visual LS.

The resulting correlation coefficients were analyzed according to Davis adjectives (Davis, 1971), in which $r=1$ indicates a perfect correlation; $0.70<r<0.99$ represents a very high correlation; $0.50<r<0.69$ shows a substantial correlation; $0.30<r<0.49$ indicates a moderate correlation; $0.10<r<0.29$ shows a low correlation; and, $0.01<r<0.09$ refers to a negligible correlation. A negative correlation is related to the negative side of the ILS scale (or left-side LS) 
and a positive correlation is related to the positive side of the ILS scale (or right-side LS) for each dimension.

\section{Results and Discussion}

Regarding the 43 students who took the pretest (24 in the COA course and 19 in the HCI course), Table 3 presents the proportion of them who scored above, equally or below the overall pretest median. The minimum and maximum obtained scores were zero and nine, respectively.

Table 3 - Proportion of students who scored above, equally or below the overall pretest median.

\begin{tabular}{cccc}
\hline \multirow{2}{*}{ Course } & \multirow{2}{*}{$\boldsymbol{n}^{\mathbf{1}}$} & \multicolumn{2}{c}{ Pretest Score } \\
\cline { 2 - 4 } & & Below/Equal $^{\mathbf{2}}$ & Above $^{\mathbf{3}}$ \\
\hline COA & 24 & 15 & 9 \\
HCI & 19 & 9 & 10 \\
\hline${ }^{1} n:$ number of students who took the pretest in each course. \\
2Below/Equal: number of students who scored values below or equal to \\
the median. ${ }^{3}$ Above: number of students who scored above the median.
\end{tabular}

Altogether, 24 students scored values below or equal to the median (15 in COA course and 9 in HCI course), whereas 19 students scored values above the median (9 in COA course and 10 in HCI course). Thereafter, correlations between the LS of students who participated in this study were also analyzed in relation to the prior knowledge test which was carried out right at the beginning of the observed semester. The overall pretest median of 43 students from two courses resulted into 2 points. Thus, two groups were created, one including students who scored less than or equal to the overall median, and the second one with students who scored higher than the overall median, as shown in Table 4.

Table 4 - Spearman correlation coefficients between scores obtained by students in the pretest and their respective LS.

\begin{tabular}{rlcccc}
\hline \multirow{2}{*}{ Group $^{\mathbf{1}}$} & \multirow{2}{*}{$\boldsymbol{n}^{\mathbf{2}}$} & \multicolumn{4}{c}{ Learning Styles } \\
\cline { 3 - 6 } & & Act/Ref & Sen/Int & Vis/Ver & Seq/Glo \\
\hline 1 & 24 & -0.242 & 0.322 & -0.083 & 0.414 \\
2 & 19 & 0.426 & -0.339 & 0.257 & -0.684 \\
\hline${ }^{1}$ Group 1: students who scored less than or equal to the overall median in the pretest; \\
Group 2: students who scored more than the overall median in the pretest. \\
${ }^{2} n$ : sample size.
\end{tabular}

Resulting values for the Spearman correlation coefficient indicate that students in the low prior knowledge group tended to be classified towards the Intuitive and Global LSs (both obtained a moderate correlation) in analyzed courses. According to the FSLSM definition, these LSs point out to students who prefer abstract content, including content overviews, and students who learn new concepts quickly but may behave in a careless way. There was also a low correlation with the active LS, indicating a tendency to people who enjoy group working.

On the other hand, in the group of students classified with high prior knowledge about each selected domain, moderate correlations were found for Reflective and Sensing LS, and a substantial correlation for Sequential LS. This result indicates that those students prefer facts and concrete content along with a linear reasoning process, which indicates that they may be slower for acquiring knowledge, however, they learn more carefully.

In many Computer Science-related courses, there is a trend to use a top-down approach for teaching, that is, a complex model is presented before its details in order to show its final goals. It is possible to imagine, for example, in a COA course, in which a high-level architectural diagram can represent an abstract content and, as each component is specified and explained, the content becomes each time more concrete and tangible. In this way, it makes sense to imagine that the Intuitive and Global LSs walk together for students in the low prior knowledge group. On 
the other hand, with a high prior knowledge, in which details and concrete facts about the content are already known, the correlations indicate another direction, that is, Sensing, Reflective, and Sequential LS.

After observing the prior knowledge factor, we tried to understand the interaction types in each one of these groups, separated by course. Table 5 exhibits the correlations results obtained for each group. Moderate and substantial correlations were found in both sub-samples of the two courses. The most expressive result is related to the HCI course, in which all correlations for the Vis/Ver dimension pointed out to the Visual LS, including a very high correlation in the high prior knowledge group regarding the number of quizzes answered by students. We believe that this result is directly related to the nature of the HCI course, since it contemplates a lot of visual elements of software interfaces.

Table 5 - Spearman correlation coefficients between types of interaction and students' LS in low and high prior knowledge groups.

\begin{tabular}{|c|c|c|c|c|c|c|}
\hline Group $^{1}$ & $n^{2}$ & Interaction & Act/Ref & Sen/Int & Vis/Ver & Seq/Glo \\
\hline \multirow{2}{*}{$\downarrow(\mathrm{C})$} & \multirow{2}{*}{15} & Quiz answering & -0.434 & -0.157 & -0.516 & -0.165 \\
\hline & & Collaborative activities & -0.147 & -0.321 & 0.019 & -0.189 \\
\hline \multirow{2}{*}{$\uparrow(\mathrm{C})$} & \multirow{2}{*}{9} & Quiz answering & 0.211 & -0.456 & -0.210 & -0.208 \\
\hline & & Collaborative activities & 0.522 & 0.090 & 0.157 & 0.165 \\
\hline \multirow{2}{*}{$\downarrow(\mathrm{H})$} & \multirow{2}{*}{9} & Quiz answering & 0.151 & -0.490 & -0.354 & -0.440 \\
\hline & & Collaborative activities & 0.238 & 0.244 & -0.054 & -0.141 \\
\hline \multirow{2}{*}{$\uparrow(\mathrm{H})$} & \multirow{2}{*}{10} & Quiz answering & -0.229 & 0.458 & -0.768 & -0.381 \\
\hline & & Collaborative activities & -0.262 & 0.182 & -0.561 & -0.572 \\
\hline
\end{tabular}

${ }^{1} \downarrow$ : students who scored less than or equal to the overall median in the pretest; $\uparrow:$ students who scored more than the overall median in the pretest; (C) COA course; (H) HCI course. ${ }^{2} n$ : sample size.

Besides, the COA course presented another interesting result. The low prior knowledge group demonstrated a tendency to the Active LS for both interaction types, while the high prior knowledge group presented an opposite tendency, pointing out to the Reflective LS. This may be a clue indicating that students who do not know the subject seek to work in groups to build their knowledge, using, for example, quizzes as a verification of it. Whereas, those students who already know the proper subjects have more confidence to classify the content according to their relevance.

\section{Conclusions}

This article presented a computational architecture that blends contextual, cognitive, social and collaborative aspects to offer adaptive learning features to students in ULEs. The resulting approach allows the assessment of students learning styles according to a probabilistic proposal of the FSLSM. To handle underlying uncertainties on competing dimensions, our associated SM is initialized with values representing $50 \%$ of suitability for each LS. As students' LSs are assessed, inferences about their possible learning preferences are performed and the probabilistic model is updated.

A prototype of the proposed model was integrated into a real ULE, which served as a case study for performing a series of experiments with technology students. Results showed that groups of students with low prior knowledge in the tested courses have a moderate correlation with Intuitive and Global LSs, which may be related to the nature of the courses. Students in the high prior knowledge group presented correlations with LSs in opposite directions, that is, Reflective (moderate correlation) and Sequential (substantial correlation) LSs. In addition, the types of interaction with the system in each of these groups may also indicate different preferences for each course. 
As future work, we expect to replace LSs by other cognitive theories, such as multiple intelligences, for example, as well as running experiments in other subject areas, such as Geography or Biology. Also, exploring approaches based on interaction patterns in online environments could provide a refinement of the SM and allow adjustments in the model initialization process.

\section{Acknowledgements}

The authors are grateful for the support of FAPEMIG, CNPq, IFSULDEMINAS, FACOM/PPGCO/PROAP/UFU, PROPP/UFU and PET/MEC/SESu. This study was financed in part by the Coordenação de Aperfeiçoamento de Pessoal de Nível Superior - Brasil (CAPES) Finance Code 001.

\section{References}

Abowd, G. D., Atkeson, C. G., Feinstein, A., Hmelo, C., Kooper, R., Long, S., ... Tani, M. (1996). Teaching and Learning as Multimedia Authoring: The Classroom 2000 Project. In Proceedings of the 4th ACM International Conference on Multimedia (pp. 187-198). Boston, Massachusetts, USA: ACM Press. doi: 10.1145/244130.244191 [GS Search]

Adkins, D., \& Guerreiro, M. (2018). Learning styles: Considerations for technology enhanced item design. British Journal of Educational Technology, 49(3), 574-583. doi: 10.1111/bjet.12556 [GS Search]

Ahmad, N., Tasir, Z., Kasim, J., \& Sahat, H. (2013). Automatic Detection of Learning Styles in Learning Management Systems by Using Literature-based Method. Procedia - Social and Behavioral Sciences, 103, 181-189. doi: 10.1016/j.sbspro.2013.10.324 [GS Search]

Alshammari, M., Anane, R., \& Hendley, R. J. (2015). The Impact of Learning Style Adaptivity in Teaching Computer Security. In Proceedings of the 2015 ACM Conference on Innovation and Technology in Computer Science Education (pp. 135-140). Vilnius, Lithuania: ACM. doi: $\underline{10.1145 / 2729094.2742614}$ [GS Search]

Alzain, A., Clark, S., Ireson, G., \& Jwaid, A. (2018). Learning Personalization Based on Learning Style instruments. Advances in Science, Technology and Engineering Systems Journal, 3(3), 108-115. doi: 10.25046/aj030315 [GS Search]

An, D., \& Carr, M. (2017). Learning styles theory fails to explain learning and achievement: Recommendations for alternative approaches. Personality and Individual Differences, 116, 410-416. doi: 10.1016/j.paid.2017.04.050 [GS Search]

Araújo, R. D. (2017). A Computational Architecture for Learning Objects Authoring and Personalization in Ubiquitous Learning Environments (Doctoral dissertation, Universidade Federal de Uberlândia, Brazil). Retrieved from https://repositorio.ufu.br/handle/123456789/20375. doi: $\underline{\text { 10.14393/UFU.TE.2018.9 [GS }}$ Search]

Araújo, R. D., Brant-Ribeiro, T., Ferreira, H. N. M., Dorça, F. A., \& Cattelan, R. G. (2016). Segmentação Colaborativa de Objetos de Aprendizagem Utilizando Bookmarks em Ambientes Educacionais Ubíquos. In Proceedings of the XXVII Brazilian Symposium on Computers in Education (SBIE 2016) (pp. 1205-1214). Uberlândia, MG, Brazil: SBC. doi: 10.5753/cbie.sbie.2016.1205 [GS Search]

Araújo, R. D., Brant-Ribeiro, T., Freitas, R. S. de, Dorça, F. A., \& Cattelan, R. G. (2014). Autoria 
automática de objetos de aprendizagem a partir de captura multimídia e associação a estilos de aprendizagem. In Proceedings of the XXV Brazilian Symposium on Computers in Education (SBIE 2014) (pp. 229-238). Dourados, MS, Brazil: SBC. doi: 10.5753/cbie.sbie.2014.229 [GS Search]

Araújo, R. D., Brant-Ribeiro, T., Mendonça, I. E., Mendes, M. M., Dorça, F. A., \& Cattelan, R. G. (2017). Social and Collaborative Interactions for Educational Content Enrichment in ULEs. Educational Technology \& Society, 20(3). [GS Search]

Barbosa, D. N. F., Barbosa, J. L. V., Bassani, P. B. S., Rosa, J., Martins, M., \& Nino, C. (2013). Content Management in a Ubiquitous Learning Environment. International Journal of Computer Applications in Technology, 46(1), 24-35. doi: 10.1504/IJCAT.2013.051385 [GS Search]

Bonate, P. L. (2000). Analysis of Pretest-Posttest Designs (1st ed.). Chapman and Hall/CRC. [GS Search]

Boticario, J. G., Rodriguez-Ascaso, A., Santos, O. C., Raffenne, E., Montandon, L., Roldán, D., \& Buendía, F. (2012). Accessible Lifelong Learning at Higher Education: Outcomes and Lessons Learned at two Different Pilot Sites in the EU4ALL Project. Journal of Universal Computer Science, 18(1), 62-85. doi: 10.3217/jucs-018-01-0062 [GS Search]

Brusilovsky, P. (2001). Adaptive Hypermedia. User Modeling and User Adapted Interaction, 11(1), 87-110. doi: 10.1023/A:1011143116306 [GS Search]

Clemente, J., Ramírez, J., \& de Antonio, A. (2011). A Proposal for Student Modeling Based on Ontologies and Diagnosis Rules. Expert Systems with Applications, 38(7), 8066-8078. doi: 10.1016/j.eswa.2010.12.146 [GS Search]

CLEO. (2003). CLEO Extensions to the IEEE Learning Object Metadata (Tech. Rep.). Redmond, WA: CLEO Collaborative Partners (Cisco Systems, Inc., IBM Corporation, Microsoft Corporation, Thomson NETg). Retrieved from https://www.oasisopen.org/committees/download.php/20490

Davis, J. A. (1971). Elementary Survey Analysis. Englewood Cliffs, NJ: Prentice-Hall. [GS Search]

Dorça, F. A., Araújo, R. D., Carvalho, V. C., Resende, D. T., \& Cattelan, R. G. (2016). An Automatic and Dynamic Approach for Personalized Recommendation of Learning Objects Considering Students Learning Styles: An Experimental Analysis. Informatics in Education, 15(1), 45-62. doi: 10.15388/infedu.2016.03 [GS Search]

Dorça, F. A., Lima, L. V, Fernandes, M. A., \& Lopes, C. R. (2013). Comparing strategies for modeling students learning styles through reinforcement learning in adaptive and intelligent educational systems: An experimental analysis. Expert Systems with Applications, 40(6), 2092-2101. doi: 10.1016/j.eswa.2012.10.014 [GS Search]

El-Bishouty, M. M., Chang, T.-W., Graf, S., Kinshuk, \& Chen, N.-S. (2014). Smart e-course recommender based on learning styles. Journal of Computers in Education, 1(1), 99-111. doi: $10.1007 / \mathrm{s} 40692-014-0003-0$ [GS Search]

Essalmi, F., Ayed, L. J. Ben, Jemni, M., Graf, S., \& Kinshuk. (2015). Generalized metrics for the analysis of E-learning personalization strategies. Computers in Human Behavior, 48, 310322. doi: $10.1016 /$ j.chb.2014.12.050 [GS Search]

Faria, A. R., Almeida, A., Martins, C., Gonçalves, R., \& Figueiredo, L. (2015). Personality traits, Learning Preferences and Emotions. In Proceedings of the Eighth International $C^{*}$ Conference on Computer Science \& Software Engineering (pp. 63-69). ACM. doi: 


\section{$\underline{10.1145 / 2790798.2790809}$ [GS Search]}

Felder, R. M., \& Silverman, L. K. (1988). Learning and teaching styles in engineering education. Journal of Engineering Education, 78(7), 674-681. [GS Search]

Felder, R. M., \& Soloman, B. A. (n.d.). Index of Learning Styles. Retrieved August 20, 2012, from http://www.ncsu.edu/felder-public/ILSpage.html

Felder, R. M., \& Spurlin, J. (2005). Applications, Reliability and Validity of the Index of Learning Styles. International Journal of Engineering Education, 21(1), 103-112. [GS Search]

Ferreira, H. N. M., Brant-Ribeiro, T., Araújo, R. D., Dorça, F. A., \& Cattelan, R. G. (2016). An Automatic and Dynamic Student Modeling Approach for Adaptive and Intelligent Educational Systems Using Ontologies and Bayesian Networks. In Proceedings of the IEEE 28th International Conference on Tools with Artificial Intelligence (pp. 738-745). doi: 10.1109/ICTAI.2016.0116 [GS Search]

Graf, S., Chang, T.-W., Kersebaum, A., Rath, T., \& Kurcz, J. (2014). Investigating the Effectiveness of an Advanced Adaptive Mechanism for Considering Learning Styles in Learning Management Systems. In Proceedings of the 14th IEEE International Conference on Advanced Learning Technologies (pp. 112-116). doi: 10.1109/ICALT.2014.41 [GS Search]

Greiff, S., Niepel, C., Scherer, R., \& Martin, R. (2016). Understanding students’ performance in a computer-based assessment of complex problem solving: An analysis of behavioral data from computer-generated log files. Computers in Human Behavior, 61, 36-46. doi: 10.1016/j.chb.2016.02.095 [GS Search]

IEEE. (2002). LTSC 1484.12.1, Draft Standard for Learning Object Metadata. Learning Technology Standards Committee of the IEEE. Retrieved from http://ltsc.ieee.org/wg12/files/LOM_1484_12_1_v1_Final_Draft.pdf

Kirschner, P. A. (2017). Stop propagating the learning styles myth. Computers \& Education, 106, 166-171. doi: 10.1016/j.compedu.2016.12.006 [GS Search]

Li, N., Cohen, W. W., Koedinger, K. R., \& Matsuda, N. (2011). A Machine Learning Approach for Automatic Student Model Discovery. In Proceedings of the 4th International Conference on Educational Data Mining (pp. 31-40). IEDMS. [GS Search]

Mahnane, L., \& Hafidi, M. (2015). Development and Testing of New E-Learning Hypermedia System. International Journal of Information Technology and Web Engineering, 10(2), 115. doi: 10.4018/IJITWE.2015040101 [GS Search]

Mahnane, L., Laskri, M. T., \& Trigano, P. (2013). A Model of Adaptive e-learning Hypermedia System based on Thinking and Learning Styles. International Journal of Multimedia and Ubiquitous Engineering, 8(3), 339-350. [GS Search]

Monteiro, B. de S., Oliveira, E., Gomes, A. S., \& Mendes Neto, F. M. (2017). Youubi: Ubiquitous Learning Environment. Brazilian Journal of Computers in Education, 25(01), 94-113. doi: 10.5753/rbie.2017.25.01.94 [GS Search]

Nguyen, Q., Rienties, B., Toetenel, L., Ferguson, R., \& Whitelock, D. (2017). Examining the designs of computer-based assessment and its impact on student engagement, satisfaction, and pass rates. Computers in Human Behavior, 76, 703-714. doi: 10.1016/j.chb.2017.03.028 [GS Search]

Onah, D. F. O., \& Sinclair, J. E. (2015). Massive Open Online Courses - An Adaptive Learning Framework. In Proceedings of the 9th International Conference on Technology, Education and Development (pp. 1258-1266). Madrid, Spain: IATED. [GS Search] 
Pimentel, M. da G., Ishiguro, Y., Kerimbaev, B., Abowd, G. D., \& Guzdial, M. (2001). Supporting Educational Activities through Dynamic Web Interfaces. Interacting with Computers, Special Issue on Interacting with the Active Web, 13(3), 353-374. doi: 10.1016/S09535438(00)00042-4 [GS Search]

Santos, O. C., Boticario, J. G., Raffene, E., \& Pastor, R. (2007). Why using dotLRN? UNED use cases. In Proceedings of the FLOSS (Free/Libre/Open Source Systems) International Conference 2007 (pp. 195-212). Jerez de la Frontera, Spain: Universidad de Cadiz. [GS Search]

Self, J. A. (1990). Bypassing the intractable problem of student modelling. Intelligent tutoring systems: At the crossroads of artificial intelligence and education, 41, 1-26. [GS Search]

Sottilare, R. A., Brawner, K. W., Sinatra, A. M., \& Johnston, J. H. (2017). An Updated Concept for a Generalized Intelligent Framework for Tutoring (GIFT) (Tech. Rep.). Orlando, USA: U.S. Army Research Laboratory - Human Research \& Engineering Directorate (ARLHRED). [GS Search]

Thomson, D., \& Mitrovic, A. (2009). Towards a negotiable student model for constraint-based ITSs. In Proceedings of the 17th International Conference on Computers in Education (pp. 83-90). Hong Kong: Asia-Pacific Society for Computers in Education. [GS Search]

Van Assche, F., Campbell, L. M., Rifón, L. A., \& Willem, M. (2003). Semantic interoperability: use of vocabularies with learning object metadata. In Proceedings of the 3rd IEEE International Conference on Advanced Learning Technologies (pp. 511-514). IEEE. doi: 10.1109/ICALT.2003.1215220 [GS Search]

Vidal, I. M. G., Costa, E. de B., Silva, L. D. da, Araújo, F. F. de, \& Ferreira, R. (2016). A Hypermedia-based Adaptive Educational System for Assisting Students in Systems and Information Technology Domain for Accountability. In Á. Rocha, A. M. Correia, H. Adeli, L. P. Reis, \& M. M. Teixeira (Eds.), New Advances in Information Systems and Technologies,Volume 2 (pp. 277-286). Springer, Cham. doi: 10.1007/978-3-319-31307$\underline{8} 28$ [GS Search]

Weiser, M. (1991). The computer for the 21st century. Scientific American, 265(3), 94-104. [GS Search]

Wiley, D. A. (2000). Connecting learning objects to instructional design theory: A definition, a metaphor, and a taxonomy. The Instructional Use of Learning Objects: Online Version. Bloomington, Indiana, USA: The Agency for Instructional Technology. Retrieved from https://reusability.org/read/ [GS Search]

Yang, T.-C., Hwang, G.-J., \& Yang, S. J.-H. (2013). Development of an Adaptive Learning System with Multiple Perspectives based on Students' Learning Styles and Cognitive Styles. Educational Technology \& Society, 16(4), 185-200. [GS Search]

Zhao, X., \& Okamoto, T. (2011). Adaptive multimedia content delivery for context-aware ulearning. International Journal of Mobile Learning and Organisation, 5(1), 46-63. doi: 10.1504/IJMLO.2011.038691 [GS Search] 